\title{
Gender differences in suicide attempters: a retrospective study of precipitating factors for suicide attempts at a critical emergency unit in Japan
}

\author{
Ryuichiro Narishige ${ }^{1}$, Yoshitaka Kawashima ${ }^{1,2}$, Yasushi Otaka ${ }^{1}$, Takuya Saito ${ }^{1,3}$ and Yoshiro Okubo ${ }^{1 *}$
}

\begin{abstract}
Background: There is a shortage of empirical data concerning precipitating factors for suicides in Japan. The purpose of the present study was to clarify gender differences of precipitating factors for suicide attempts in Japan.

Methods: The subjects were high-lethality suicide attempters who were admitted to the Nippon Medical School Hospital Critical Care Medical Center between March 1, 2010 and March 31, 2012. Precipitating factors for suicide attempt, method of suicide attempt, psychiatric diagnoses and other sociodemographic data were collected from the patients' medical records retrospectively, and statistical analyses were performed for categorical variables of male/female.

Results: The total number of subjects was 193 (88 males and 105 females). The rate of subjects attempting suicide by poisonous gas was significantly higher in males while that of subjects attempting suicide by drug overdose was significantly higher in females. The rate of subjects diagnosed with "major depressive disorder, bipolar disorder" was significantly higher in males while that of subjects diagnosed with "personality disorders" or "dysthymic disorder" was significantly higher in females. Subjects with "health problems", "financial problems", "work problems", "debts (others)" or "unwanted transfer" were significantly more numerous among males; subjects with "family problems", "parent-child relations" or "Ioneliness" were significantly more frequently found among females.

Conclusions: Mental disorders were the most common precipitating factor for suicide attempts regardless of gender. Significant gender differences were observed in psychiatric diagnoses, methods of suicide attempt and psychosocial problems. This indicates the necessity of suicide prevention measures corresponding to these gender differences.
\end{abstract}

Keywords: Suicide attempters, Precipitating factors for suicides, Gender differences, Critical care medical center

\section{Background}

In Japan, the number of suicides has been decreasing in recent years but has remained at around 30,000 annually after a sudden increase in 1998. Suicide prevention measures have been taken by the whole nation to reduce suicides after the Basic Act on Suicide Prevention was enacted in 2006. On the other hand, it is difficult to narrow down which measures should be taken intensively

\footnotetext{
* Correspondence: okubo-y@nms.ac.jp

1Department of Neuropsychiatry, Nippon Medical School, 1-1-5 Sendagi, Bunkyo-ku, Tokyo 113-8603, Japan

Full list of author information is available at the end of the article
}

because empirical data regarding precipitating factors for suicides are insufficient in Japan.

Some previous studies have endeavored to clarify the characteristics of suicide-related behaviors in Japan by investigating suicide attempts [1-4]. However, in those studies, investigations focused only on psychiatric diagnoses or sociodemographic data of suicide attempters, and precipitating factors for suicide attempts were not examined. Pompili argued that suicide is better understood as a phenomenon centered in the individual [5]. Analysis of subjective motives as well as analysis of objective risk factors is useful for understanding suicide. The National Police Agency (NPA) yearly announces the 
annual number of suicides, and analysis of the precipitating factors for suicides based on the NPA's suicide statistics is made public simultaneously. However, it is possible that the actual state of suicides has not been grasped correctly in this analysis due to inadequate psychiatric assessment, and precipitating factors for suicides were specified in only about $70 \%$ of suicide committers in the NPA's suicide statistics [6].

Gender differences in suicide-related behavior are wellknown. Females have a higher rate of suicide attempts than males, while males have a higher rate of mortality from suicide than females [7-9]. The male/female ratio of suicide attempts is $0.65-0.81$ according to previous studies in Japan [1-4]. Females are more likely to attempt suicide by poisoning than males, while males are more likely to use methods of suicide with high lethality like hanging than females [8,9]. In addition to these characteristics, some gender differences in sociodemographic characteristics of suicide committers or attempters are known. Regarding the sociodemographic characteristics of suicide committers in Denmark, Qin et al. reported that being single, unemployed and having a low income were associated with higher suicide risk in males, whereas having a young child was associated with lower suicide risk in females [10]. Fekete et al. reported sociodemographic characteristics of suicide attempters in Hungary, including that females were economically inactive or widowed and males were unemployed or living alone [11]. Zhang et al. studied the sociodemographic characteristics of suicide attempters in American young adults, reporting that low income and smoking were associated with suicide attempts in males, and poor self-evaluated health, low educational attainment and drug use were associated with suicide attempts in females [12]. However, gender differences of precipitating factors for suicide-related behavior have been insufficiently investigated. Wu et al. reported that unemployment or economic problems were regarded as significant precipitating factors for suicide attempts to a greater extent in males than in females in Taiwan, but the sample consisted mainly of people with a suicide lethality ranging from mild to moderate [13]. Tóth et al. reported that interpersonal conflict was found to be the most frequent precipitating factor for suicide attempts by deliberate self-poisoning in Hungary and also that male suicide attempters with interpersonal conflicts had lower levels of depression [14].

In the present study, we investigated precipitating factors for suicide attempts from the data of suicide attempters admitted to the Nippon Medical School Hospital Critical Care Medical Center. Gender differences in Japanese suicide-related behavior have not been clarified. Thus, we aimed to clarify the gender differences in precipitating factors for suicide attempts in Japan.

We previously reported a study concerning precipitating factors for suicide attempts based on a preliminary psychiatric assessment of suicide attempters, in which we explored the precipitating factors for suicide attempts among adolescent suicide attempters [15]. In the present study, we comprehensively investigated precipitating factors for suicide attempts via an approach unprecedented in Japan.

\section{Methods \\ Study design and sample}

The subjects were suicide attempters with high lethality who were admitted to the Nippon Medical School Hospital Critical Care Medical Center. All patients admitted to this facility are in medically serious and fatal condition. About 2,000 patients are admitted every year, and about $5 \%$ of them are suicide attempters excluding suicide committers. The study period was from March 1, 2010 to March 31, 2012.

In this report, the term "suicide attempt" follows the Columbia Classification Algorithm of Suicide Assessment (C-CASA), i.e., it is defined as a potentially selfinjurious behavior, associated with at least some intent to die, as a result of the act [16]. We adopted this definition of the term "suicide attempt" because it is often clinically used. Silverman et al. proposed the nomenclature for suicidology, defining "suicide attempt" as a self-inflicted, potentially injurious behavior with a nonfatal outcome for which there is evidence of intent to die $[17,18]$. There is no essential difference between CCASA and the nomenclature proposed by Silverman et al. in respect to the definition of the term "suicide attempt".

At the Nippon Medical School Hospital Critical Care Medical Center, psychiatrists examine all suicide attempters and confirm their intent to die when they attempted suicide. Psychiatrists assess their mental state and problems that precipitated their suicide attempt. Psychiatric diagnoses were made according to the DSM-IV-TR criteria [19] by agreement among two or more experienced psychiatrists. Psychiatrists also assessed precipitating factors for the suicide attempts. Precipitating factors for suicide attempt, methods of suicide attempt, psychiatric diagnoses and other sociodemographic data were collected from the patients' medical records retrospectively. If the subject had attempted suicide by two or more methods, we only presented the most lethal one.

Precipitating factors for suicide attempts were classified in accordance with the items used for the classification of precipitating factors for suicides by the NPA's 2010 suicide statistics (Table 1) [6]. These are the only official statistics that include data on precipitating factors for suicides, and they are widely used as the basic data for suicide prevention in Japan. This is why the classification by the NPA's suicide statistics was used in the present study. Three items or less were presented as precipitating factors for 
Table 1 Items used for classification in NPA's suicide statistics, 2010

\begin{tabular}{|c|c|}
\hline Major category & Sub-classification \\
\hline Family problems & $\begin{array}{l}\text { Parent-child relations, marital relations, relations with other family members, death in the family, pessimism over family's future, } \\
\text { scolding from family members, worries about parenting, abuse, exhaustion from nursing or care, others }\end{array}$ \\
\hline Health problems & Disease, depression, schizophrenia, alcohol dependence, drug abuse, other mental disorders, physical handicaps, others \\
\hline Financial problems & $\begin{array}{l}\text { Bankruptcy, business slump, redundancy, failure to find employment, poverty, debts (accumulated loans), debts (joint liability), } \\
\text { debts (others), repayment pressure from creditors, insurance paid by suicide, others }\end{array}$ \\
\hline Work problems & Failure in business, workplace relationship, unwanted transfer, work overload, others \\
\hline Love problems & Marriage problems, broken heart, worries about adultery, trouble with boyfriend or girlfriend, others \\
\hline School problems & Entrance examinations, career decisions, academic failure, relationship with teachers, bullying, relationship with schoolmates, others \\
\hline Other problems & Having ones' crime revealed, crime victim, suicide over someone's death, loneliness, relationship with neighbors, others \\
\hline
\end{tabular}

suicides in the NPA's 2010 suicide statistics, while more than three items were also presented as precipitating factors of suicide attempts in the present study in order to show the background of suicide attempts more accurately. The items for mental disorders in the NPA's 2010 suicide statistics ("depression", "schizophrenia", "alcohol dependence", "drug abuse" and "other mental disorders") were removed from the items in the present study because psychiatric diagnoses were made according to the DSM-IV-TR criteria independently.

If there were two or more precipitating factors belonging to the same major category in one subject, the number of precipitating factors in that major category was considered to be one only when the analysis was performed between major categories.

\section{Statistical analyses}

Statistical analyses were conducted using PASW Statistics 18 (SPSS Inc., Chicago, IL, USA). Welch's t-test was used to compare the variables of age and the number of precipitating factors between males and females. Chisquare test or Fisher's exact test was used to determine the categorical variables of being under psychiatric treatment, employment status, method of suicide attempt, psychiatric diagnosis and precipitating factors for suicide attempt between males and females. Chi-square test or Fisher's exact test was also used to determine the categorical variables of method of suicide attempt between under psychiatric treatment and no psychiatric treatment. We used a significance level of $\mathrm{p}<0.05$ and twosided probability.

\section{Ethics}

The present study was approved by the Ethics Committee of Nippon Medical School Hospital and conforms to the provisions of the Declaration of Helsinki.

\section{Results}

Characteristics of subjects

The results are shown in Table 2 .
The total number of subjects was 193 (88 males and 105 females), with the male/female ratio being 0.84 . Their mean age was $41.1 \pm 16.3$ SD years (range: 15-91 years). Sixty of the subjects (31.1\%) were employed.

Those attempting suicide by drug overdose comprised the largest group, with 101 cases (52.3\%). The second largest group, 33 cases (17.1\%), consisted of those attempting suicide by jumping from a high place. Hanging is the most common method among suicide committers in Japan, but the subjects who attempted suicide by hanging were the fifth most, with 11 cases (5.7\%).

182 of the 193 subjects (94.3\%) had mental disorders and 131 of the 193 subjects $(67.9 \%)$ were under psychiatric treatment. Those diagnosed with "mood disorders" were the most, with 68 cases (35.2\%): 36 of them were diagnosed with "major depressive disorder", 6 with "bipolar disorder", and 26 with "dysthymic disorder". The subjects diagnosed with "schizophrenia and other psychotic disorders" were the second largest group, with 45 cases (23.3\%). The third largest group, 27 cases (14.0\%), consisted of those diagnosed with "adjustment disorders". The fourth largest group consisted of "personality disorders", with 22 cases (11.4\%): 18 of them were diagnosed with "borderline personality disorder" and 4 with "personality disorder not otherwise specified".

The mean number of precipitating factors, except mental disorders, was $1.11 \pm 0.78$ SD per subject (range: $0-4)$. The subjects with "family problems" made up the largest group, with 62 cases (32.1\%). Those with "financial problems" comprised the second largest, with 40 cases $(20.7 \%)$, and those with "other problems" the third largest, with 29 cases (15.0\%).

\section{Gender differences}

There was no significant difference in mean age and mean number of precipitating factors between males and females. The proportion of employed subjects was significantly larger among males (chi-square test, $x^{2}=13.216, p=0.000$ ). $16.2 \%$ of the female subjects were housewives, and there were no house-husbands among the male subjects; the rate of subjects who were housewives or house-husbands 
Table 2 Precipitating factors of suicide attempts and gender differences

\begin{tabular}{|c|c|c|c|c|c|}
\hline & $\begin{array}{c}\text { Total } \\
(\mathrm{N}=193)\end{array}$ & $\begin{array}{l}\text { Males } \\
(\mathrm{N}=\mathbf{8 8})\end{array}$ & $\begin{array}{l}\text { Females } \\
(\mathrm{N}=105)\end{array}$ & Significance & \\
\hline Age $\pm S D$ & $41.1 \pm 16.3$ & $42.4 \pm 16.3$ & $40.1 \pm 16.4$ & $N S^{\S}$ & \\
\hline Mean number of precipitating factors \pm SD & $1.11 \pm 0.78$ & $1.20 \pm 0.87$ & $1.04 \pm 0.69$ & $N S^{\S}$ & \\
\hline Under psychiatric treatment & 131 & 50 & 81 & $p=0.003^{q}$ & $x^{2}=9.070$ \\
\hline \multicolumn{6}{|l|}{ Employment status } \\
\hline Employed & 60 & 39 & 21 & $p=0.000^{n}$ & $x^{2}=13.216$ \\
\hline Unemployed & 97 & 39 & 58 & $N S^{\natural}$ & \\
\hline Housewife or house-husband & 17 & 0 & 17 & $p=0.000^{n}$ & $x^{2}=15.624$ \\
\hline Student & 19 & 10 & 9 & $N S^{\natural}$ & \\
\hline \multicolumn{6}{|l|}{ Methods of suicide attempt } \\
\hline Drug overdose & 101 & 36 & 65 & $p=0.004^{n}$ & $x^{2}=8.460$ \\
\hline Jumping from a high place & 33 & 17 & 16 & $N S^{\pi}$ & \\
\hline Cutting & 16 & 10 & 6 & $N S^{\pi}$ & \\
\hline Poisonous gas & 15 & 13 & 2 & $p=0.001^{\natural}$ & $x^{2}=11.060$ \\
\hline Hanging & 11 & 7 & 4 & $N S^{\pi}$ & \\
\hline Poisoning & 9 & 4 & 5 & $\mathrm{NS}^{+}$ & \\
\hline Other methods & 11 & 2 & 9 & $N S^{n}$ & \\
\hline \multicolumn{6}{|l|}{ DSM-IV-TR } \\
\hline Substance-induced disorders & 16 & 11 & 5 & $N S^{\natural}$ & \\
\hline Schizophrenia and other psychotic disorders & 45 & 22 & 23 & $N S^{\sharp}$ & \\
\hline Major depressive disorder, bipolar disorder & 42 & 26 & 16 & $p=0.016^{\sharp}$ & $x^{2}=5.756$ \\
\hline Dysthymic disorder & 26 & 7 & 19 & $p=0.040^{n}$ & $x^{2}=4.224$ \\
\hline Adjustment disorders & 27 & 13 & 14 & $N S^{\pi}$ & \\
\hline Personality disorders & 22 & 2 & 20 & $p=0.000^{n}$ & $x^{2}=13.339$ \\
\hline Other psychiatric disorders & 14 & 6 & 8 & $N s^{\pi}$ & \\
\hline None & 11 & 6 & 5 & $N S^{\sharp}$ & \\
\hline \multicolumn{6}{|l|}{ Precipitating factors } \\
\hline Family problems & 62 & 20 & 42 & $p=0.010^{q}$ & $x^{2}=6.551$ \\
\hline Parent-child relations & 14 & 2 & 12 & $p=0.015^{\natural}$ & $x^{2}=5.965$ \\
\hline Health problems & 8 & 7 & 1 & $p=0.024^{\dagger}$ & \\
\hline Financial problems & 40 & 24 & 16 & $p=0.040^{q}$ & $x^{2}=4.220$ \\
\hline Debt (others) & 4 & 4 & 0 & $p=0.042^{\dagger}$ & \\
\hline Work problems & 27 & 18 & 9 & $p=0.018$ & $x^{2}=5.618$ \\
\hline Unwanted transfer & 4 & 4 & 0 & $p=0.042^{\dagger}$ & \\
\hline Love problems & 20 & 7 & 13 & $N S^{\pi}$ & \\
\hline School problems & 6 & 3 & 3 & $\mathrm{NS}^{+}$ & \\
\hline Other problems & 29 & 12 & 17 & $N S^{\pi}$ & \\
\hline Loneliness & 12 & 2 & 10 & $p=0.038^{\pi}$ & $x^{2}=4.317$ \\
\hline
\end{tabular}

${ }^{5}$ Welch's t-test, " $c h i-$-square test, ${ }^{\dagger}$ Fisher's exact test.

was significantly higher in females (chi-square test, $\left.\chi^{2}=15.624, p=0.000\right)$.

The rate of subjects attempting suicide by drug overdose was significantly higher in females (chi-square test, $\left.\chi^{2}=8.460, p=0.004\right)$, and the rate of those attempting suicide by poisonous gas was significantly higher in males (chi-square test, $\mathrm{X}^{2}=11.060, p=0.001$ ).

The number of subjects under psychiatric treatment was 50 in males (56.8\%) and 81 in females (77.1\%), with the rate being significantly higher in females (chi-square 
test, $\left.x^{2}=9.070, p=0.003\right)$. Table 3 shows the differences in the methods of suicide attempt due to the presence or absence of psychiatric treatment. The rate of subjects attempting suicide by drug overdose was significantly higher in the subjects under psychiatric treatment (chisquare test, $\chi^{2}=12.479, p=0.000$ ). On the other hand, the rates of those attempting suicide by cutting (chisquare test, $\mathrm{X}^{2}=4.657, p=0.031$ ) and poisoning (Fisher's exact test, $p=0.032$ ) were significantly lower in the subjects under psychiatric treatment.

The rate of subjects diagnosed with "major depressive disorder" or "bipolar disorder" (chi-square test, $\chi^{2}=5.756$, $p=0.016)$ was significantly higher in males, and the rate of those diagnosed with "personality disorders" (chi-square test, $X^{2}=13.339, p=0.000$ ) or "dysthymic disorder" (chi-square test, $\chi^{2}=4.224, p=0.040$ ) was significantly higher in females.

Among major categories of precipitating factors, the rates of subjects with "health problems" (Fisher's exact test, $p=0.024$ ), "financial problems" (chi-square test, $\chi^{2}=4.220, p=0.040$ ) and "work problems" (chi-square test, $X^{2}=5.618, p=0.018$ ) were significantly higher in males, whereas the rate of those with "family problems" (chi-square test, $X^{2}=6.551, p=0.010$ ) was significantly higher in females. Among sub-classifications of precipitating factors, the rate of subjects who had "debts (others)" ("financial problems") (Fisher's exact test, $p=0.042$ ) or "unwanted transfer" ("work problems") (Fisher's exact test, $p=0.042$ ) was significantly larger in males; the rate of subjects with "parent-child relations" ("family problems") (chi-square test, $\chi^{2}=5.965, p=0.015$ ) or "loneliness" ("other problems") (chi-square test, $\chi^{2}=4.317, p=0.038$ ) was significantly higher in females.

\section{Discussion}

Previous studies have shown that mental disorders are the most common precipitating factor for suicide-related behavior regardless of gender [3,20,21]. Yamada et al. reported that $95 \%$ and $65 \%$ of suicide attempters had mental disorders and were under psychiatric treatment, respectively [3]. In the present study, $94.3 \%$ of the subjects had mental disorders and $67.9 \%$ were under psychiatric treatment, percentages similar to those of the previous study. Pompili et al. reported that suicide in eating disorders is a major cause of death [22], but there was no subject with eating disorders in the present study.

The rate of subjects diagnosed with "major depressive disorder, bipolar disorder" was significantly lower, and that of subjects diagnosed with "personality disorders" and "dysthymic disorder" was significantly higher in females. Isometsä et al. compared suicide committers with unipolar depression not fulfilling the criteria of major depressive disorder with those with major depressive disorder [23]. They reported that problems in recent life events were observed more commonly among suicide committers with non-major depressive disorders, and particularly during the final week. Further, patients with personality disorder, especially borderline personality disorder, typically have high impulsivity. Considering these findings, it is possible that females might tend to attempt suicide without major depressive disorder but rather in connection with life events or impulsivity.

In the present study, the rate of subjects attempting suicide by drug overdose was significantly higher in females. It is known that females are more likely to attempt suicide by poisoning than males $[8,9]$, but we can infer from the high rate of female subjects under psychiatric treatment that they could get drugs for suicide attempts more easily than acquire items for other suicidal methods.

Male suicide attempters tend to be influenced by societal problems like "financial problems" or "work problems" and female suicide attempters by social problems

Table 3 Differences in methods of suicide attempt due to the presence or absence of psychiatric treatment

\begin{tabular}{|c|c|c|c|c|c|}
\hline & $\begin{array}{c}\text { Total } \\
(\mathrm{N}=184)\end{array}$ & $\begin{array}{c}\text { Under } \\
\text { psychiatric } \\
\text { treatment } \\
(\mathrm{N}=131)\end{array}$ & $\begin{array}{c}\text { No } \\
\text { psychiatric } \\
\text { treatment } \\
(\mathrm{N}=62)\end{array}$ & Significance & \\
\hline \multicolumn{6}{|l|}{ Methods of suicide attempt } \\
\hline Drug overdose & 101 & $80^{*}$ & 21 & $p=0.000^{\natural}$ & $x^{2}=12.479$ \\
\hline Jumping from a high place & 33 & 24 & 9 & $N S^{\pi}$ & \\
\hline Cutting & 16 & 7 & 9 & $p=0.031^{q}$ & $x^{2}=4.657$ \\
\hline Poisonous gas & 15 & 7 & 8 & $\mathrm{NS}^{+}$ & \\
\hline Hanging & 11 & 5 & 6 & $\mathrm{NS}^{+}$ & \\
\hline Poisoning & 9 & 3 & 6 & $p=0.032^{+}$ & \\
\hline Other methods & 11 & 6 & 5 & $N S^{\dagger}$ & \\
\hline
\end{tabular}

"chi-square test, ${ }^{\dagger}$ Fisher's exact test.

${ }^{*} 53$ females $(81.5 \%)$ and 27 males $(75.0 \%)$ under psychiatric treatment attempted suicide by drug overdose. 
like "parent-child relations" or "loneliness." These findings indicate that male suicide attempters tended to attempt suicide in societal situations, while female suicide attempters tended to attempt suicide in social situations. This difference between males and females may reflect the structure of Japanese society, in which social participation of females is still insufficient - the recent labor force participation rate of those aged $15-64$ years is about $80 \%$ in males and about $60 \%$ in females [24]. In the present study, the rate of those who were employed was significantly higher in males and the rate of the subjects who were housewives or house-husbands was significantly higher in females.

In the present study, the distinct gender differences were confirmed in psychiatric diagnoses, methods of suicide attempt and psychosocial problems, indicating the necessity of suicide prevention measures corresponding to these gender differences, e.g., support for solving societal problems for males and preventing psychosocial isolation for females.

\section{Limitations}

The main limitation of the present study is that the subjects were suicide attempters, i.e., they did not commit suicide. It could be argued, therefore, that the results may not accurately reflect the characteristics of suicide committers. However, suicide attempt, and especially repetitious suicide attempts, is known as a high-risk factor for subsequent suicide [25-27]. Furthermore, all of the subjects were high-lethality suicide attempters and clearly intended to kill themselves (most suicide attempters admitted to the critical care medical center use highly lethal methods in their suicide attempts), so we believe that they had very similar characteristics to those of persons who committed suicide, indicating that our results truly reflect the characteristics of suicide committers in Japan. In addition, the advantage of investigating suicide attempters is that we can directly confirm precipitating factors for suicide attempts from the attempters themselves, as well as perform psychiatric assessment regarding their mental state at the time of their suicide attempts. Therefore, investigating suicide attempters such as in the present study is considered to be an effective method for clarifying the characteristics of suicide-related behaviors.

Another limitation of the present study is that we collected the subjects' information from their medical records and did not use objective methods like structured interviews when we assessed their psychiatric diagnoses and precipitating factors for suicide attempts. Instead, we assessed the subjects' psychiatric diagnoses and precipitating factors for suicide attempts by agreement among two or more psychiatrists.

Previous suicide attempt is known as a risk factor for suicide, while it is not considered to be a precipitating factor for suicide and is not included in the classification items of the NPA's suicide statistics. Therefore, we did not include previous suicide attempt in the analysis of the present study. This might be a limitation of the present study.

\section{Conclusions}

Mental disorders were the most common precipitating factor for suicide attempts regardless of gender. This indicates the necessity for reinforcement of the mental health system as a basic suicide prevention measure. Gender differences were significantly observed in psychiatric diagnoses, methods of suicide attempt and psychosocial problems. Suicide prevention measures based on these gender differences should be performed.

\section{Abbreviations}

NPA: National police agency; C-CASA: Columbia classification algorithm of suicide assessment.

\section{Competing interests}

The authors declare that they have no competing interests.

\section{Authors' contributions}

All authors contributed to the conception and design of the study. RN, YK and $\mathrm{YO}$ contributed to data collection. RN performed the statistical analyses and wrote the first and final drafts based on a review and comments from all authors listed. All authors read and approved the final manuscript.

\section{Acknowledgements}

The present study was supported by a Health and Labour Sciences Research Grant (Comprehensive Research on Disability, Health and Welfare) from the Ministry of Health, Labour and Welfare, 2012.

\section{Author details}

'Department of Neuropsychiatry, Nippon Medical School, 1-1-5 Sendagi, Bunkyo-ku, Tokyo 113-8603, Japan. ${ }^{2}$ Department of

Neuropsychopharmacology, National Institute of Mental Health, National Center of Neurology and Psychiatry, 4-1-1 Ogawahigashi-cho, Kodaira-shi, Tokyo, Japan. ${ }^{3}$ Department of Child and Adolescent Psychiatry, Graduate School of Medicine, Hokkaido University, North 15, West 7, Kita-ku, Sapporo-shi, Japan.

Received: 18 January 2014 Accepted: 13 May 2014 Published: 19 May 2014

\section{References}

1. Ichimura A, Matsumoto $H$, Aoki T, Andoh H, Yano H, Nakagawa $Y$, Yamamoto I, Inokuchi S: Characteristics of suicide attempters with depressive disorders. Psychiatry Clin Neurosci 2005, 59:590-594.

2. Ichimura A, Matsumoto H, Kimura T, Okuyama T, Watanabe T, Nakagawa $Y$, Yamamoto I, Inokuchi S, Hosaka T: Changes in mental disorder distribution among suicide attempters in mid-west area of Kanagawa. Psychiatry Clin Neurosci 2005, 59:113-118.

3. Yamada T, Kawanishi C, Hasegawa H, Sato R, Konishi A, Kato D, Furuno T, Kishida I, Odawara T, Sugiyama M, Hirayasu Y: Psychiatric assessment of suicide in Japan: a pilot study at a critical emergency unit in an urban area. BMC Psychiatry 2007, 7:64

4. Nakagawa M, Kawanishi C, Yamada T, Sugiura K, Iwamoto Y, Sato R, Morita S, Odawara T, Hirayasu Y: Comparison of characteristics of suicide attempters with schizophrenia spectrum disorders and those with mood disorders in Japan. Psychiatry Res 2011, 188:78-82.

5. Pompili M: Exploring the Phenomenology of Suicide. Suicide Life Threat Behav 2010, 40:234-244.

6. National Police Agency: Statistics of suicide victims in Japan in 2010. (in Japanese). http://www.npa.go.jp/safetylife/seianki/jisatsu/H22/ H22_jisatunogaiyou.pdf. 
7. Canetto SS, Sakinofsky I: The gender paradox in suicide. Suicide Life Threat Behav 1998, 28:1-23.

8. Tsirigotis K, Gruszczynski W, Tsirigotis M: Gender differentiation in methods of suicide attempts. Med Sci Monit 2011, 17:H65-70.

9. Callanan VJ, Davis MS: Gender differences in suicide methods. Soc Psychiatry Psychiatr Epidemiol 2012, 47:857-869.

10. Qin P, Agerbo E, Motensen PB: Suicide risk in relation to socioeconomic, demographic, psychiatric, and familial factors a national register-based study of all suicides in Denmark, 1981-1997. Am J Psychiatry 2003, 160:765-772.

11. Fekete $S$, Voros V, Osvath P: Gender differences in suicide attempters in Hungary: retrospective epidemiological study. Croat Med J 2005, 46:288-293.

12. Zhang J, McKeown RE, Hussey JR, Thompson SJ, Woods JR: Gender differences in risk factors for attempted suicide among young adults: findings from the Third National Health and Nutrition Examination Survey. Ann Epidemiol 2005, 15:167-174.

13. Wu YW, Su YJ, Chen CK: Clinical characteristics, precipitating stressors, and correlates of lethality among suicide attempters. Chang Gung Med J 2009, 32:543-552.

14. Tóth, Adám S, Birkás E, Székely A, Stauder A, Purebl G: Gender Differences in Deliberate Self-Poisoning in Hungary. Crisis 2014, 3:1-9.

15. Kawashima $Y$, Ito T, Narishige R, Saito T, Okubo $Y$ : The characteristics of serious suicide attempters in Japanese adolescents - comparison study between adolescents and adults. BMC Psychiatry 2012, 12:191.

16. Posner K, Oquendo MA, Gould M, Stanley B, Davies M: Columbia Classification Algorithm of Suicide Assessment (C-CASA): Classification of suicidal events in the FDA's pediatric suicide risk analysis of antidepressants. Am J Psychiatry 2007, 164:1035-1043.

17. Silverman MM, Berman AL, Sanddal ND, O'Carroll PW, Joiner TE: Rebuilding the Tower of Babel: A Revised Nomenclature for the Study of Suicide and Suicidal Behaviors. Part 1: Background, Rationale and Methodology. Suicide Life Threat Behav 2007, 37:248-263.

18. Silverman MM, Berman AL, Sanddal ND, O'Carroll PW, Joiner TE: Rebuilding the Tower of Babel: A Revised Nomenclature for the Study of Suicide and Suicidal Behaviors Part 2: Suicide-Related Ideations, Communications, and Behaviors. Suicide Life Threat Behav 2007, 37:264-277.

19. American Psychiatric Association: Diagnostic and Statistical Manual of Mental Disorders, Fourth Edition, Text Revision (DSM-IV-TR). Washington DC: American Psychiatry Association 2000.

20. Asukai N: Mental Disorder as a Risk Factor of Suicide; A Clinical Study of Failed Suicides. Seishin Shinkeigaku Zasshi 1994, 96:415-443 (in Japanese).

21. Bertolote JM, Fleischmann A: Suicide and psychiatric diagnosis: a worldwide perspective. World Psychiatry 2002, 1:181-185.

22. Pompili M, Girardi P, Tatarelli G, Ruberto A, Tatarelli R: Suicide and attempted suicide in eating disorders, obesity and weight-image concern. Eat Behav 2006, 7:384-394.

23. Isometsä E, Heikkinen M, Henriksson M, Aro H, Marttunen M, Kuoppasalmi K, Lönnqvist J: Suicide in non-major depressions. J Affect Disord 1996, 36:117-127.

24. Annual Report on the Labour Force Survey 2012. http://www.stat.go.jp/ english/data/roudou/report/2012/index.htm.

25. Beautrais $A$ : Subsequent mortality in medically serious suicide attempts: a 5 year follow-up. Aust N Z J Psychiatry 2003, 37:595-599.

26. Nordström P, Samuelson M, Asberg M: Survival analysis of suicide risk after attempted suicide. Acta Psychiatr Scand 1995, 91:336-340.

27. Owens D, Horrocks J, House A: Fatal and non fatal repetition of self-harm. Systematic review. Br J Psychiatry 2002, 181:193-199.

doi:10.1186/1471-244X-14-144

Cite this article as: Narishige et al:: Gender differences in suicide attempters: a retrospective study of precipitating factors for suicide attempts at a critical emergency unit in Japan. BMC Psychiatry 2014 14:144.

\section{Submit your next manuscript to BioMed Central and take full advantage of:}

- Convenient online submission

- Thorough peer review

- No space constraints or color figure charges

- Immediate publication on acceptance

- Inclusion in PubMed, CAS, Scopus and Google Scholar

- Research which is freely available for redistribution

Submit your manuscript at www.biomedcentral.com/submit
Ciomed Central 